\title{
Measuring European property investment performance: comparing different approaches
}

Article

Accepted Version

Devaney, S. (2014) Measuring European property investment performance: comparing different approaches. Journal of European Real Estate Research, 7 (1). pp. 112-132. ISSN 1753-9269 doi: https://doi.org/10.1108/JERER-10-2013-0022 Available at https://centaur.reading.ac.uk/36445/

It is advisable to refer to the publisher's version if you intend to cite from the work. See Guidance on citing.

Published version at: http://www.emeraldinsight.com/journals.htm?articleid=17108982

To link to this article DOI: http://dx.doi.org/10.1108/JERER-10-2013-0022

Publisher: Emerald Group Publishing

All outputs in CentAUR are protected by Intellectual Property Rights law, including copyright law. Copyright and IPR is retained by the creators or other copyright holders. Terms and conditions for use of this material are defined in the End User Agreement.

www.reading.ac.uk/centaur

\section{CentAUR}


Central Archive at the University of Reading

Reading's research outputs online 


\title{
Measuring European Property Investment Performance: Comparing Different Approaches
}

\author{
Dr Steven Devaney \\ Real Estate and Planning, Henley Business School, \\ University of Reading, Whiteknights, Reading, RG6 6UD, United Kingdom \\ E-mail: s.devaney@henley.reading.ac.uk \\ Web: www.henley.ac.uk/people/person/dr-steven-devaney/
}

Published in 2014 in the Journal of European Real Estate Research, Vol. 7, Issue 1, Pages 112-132

DOI: 10.1108/JERER-10-2013-0022

\begin{abstract}
Price indices for commercial real estate markets are difficult to construct because properties are heterogeneous, they are spatially dispersed and they are infrequently traded. Appraisal indices are one response to these problems, but they may understate volatility or fail to capture turning points in a timely manner. This paper estimates 'Transaction Linked Indices' for major European markets to see whether these offer a different perspective on market performance. The assessed value method is used to construct these indices. The underlying data comprise appraisals and sale prices for assets monitored by Investment Property Databank. The indices are compared to appraisal based series for the countries concerned for Q4 2001 to Q4 2012. Transaction Linked Indices show stronger growth and sharper declines over the course of the cycle, but they do not notably lead their appraisal based counterparts. They are typically two to four times more volatile. The indicators offer alternative estimates of real estate market volatility that may be useful in asset allocation and risk modelling. However, they have some limitations; for instance, only country level indicators can be constructed in many cases owing to low trading volumes in the period studied.
\end{abstract}

\section{Acknowledgments}

The author thanks lan Cullen and Mark Clacy-Jones at Investment Property Databank for their support and funding of research in this area and Valentina Liouri for assistance with data. Earlier drafts were presented at the European Central Bank, the University of Cambridge and Hull University Business School. The views expressed and any mistakes or omissions are the responsibility of the author alone. 


\section{Introduction}

Indices of investment performance and prices are a fundamental part of the information landscape for major investment asset classes. They assist investors in both the monitoring of performance and the formulation of investment strategies through modelling and forecasting. Such indices are also of interest to economists and policy makers, particularly in the context of monitoring financial systems and the risks being taken by participants within those systems. This includes the risks being borne by certain types of investors, such as insurance companies, and the risks faced by lenders from changes in asset prices. In Europe, given the importance of commercial real estate both as loan collateral and as an alternative asset class for institutional investors, it is unsurprising that demand for indices of real estate prices and performance has risen.

However, index construction for commercial real estate is complicated by the heterogeneity of the assets concerned and the infrequent and irregular trading of these assets. Furthermore, the lack of a central, public exchange for real estate assets presents difficulties for obtaining the data needed to produce robust performance measures. For these reasons, appraisal based indices predominate in the measurement of commercial real estate performance. These are possible owing to the obligation in many countries for certain types of investors to regularly reappraise their real estate assets. These appraisals are based on definitions that require the estimated value to represent the price that the asset is expected to sell for at that time. In principle, they can be used as proxies for price in the absence of regular, repeated trading, but the frequency of such appraisals may be low. In fact, for many European countries, the available appraisal indices are only annual in frequency and have short time series.

Meanwhile, an extensive theoretical literature has arisen that highlights problems with appraisal based series. Some of the issues relate to micro-level appraisal processes while others concern the aggregation of appraisals into a market level index. Micro-level issues revolve around the availability of timely transaction evidence and the selection and weighting of such evidence within the appraisal process. Clayton et al. (2001) consider rational and behavioural explanations for the incorporation of both current and past price information into appraisals. A partial reliance on past information when conducting individual appraisals may be justifiable in the context of infrequent and noisy transaction price signals. However, any systematic tendency in appraisals to rely on past evidence is problematic for indices as the smoothing effects cannot be removed when appraisals are aggregated [1].

This suggests that appraisal based indices will provide a smoothed and lagged representation of price movements in real estate markets. This then poses problems for analyses based on such series. If volatility is understated and turning points are not captured, this affects risk-return comparisons and relationships with other economic and financial variables. In particular, realistic measurement of real estate risk is of concern given current regulatory initiatives such as Solvency II that seek to limit the exposure of financial institutions to asset price changes. At an international level, the picture is further complicated by inconsistencies in practice across different appraisal regimes. Despite efforts to harmonise definitions through creation of international valuation standards, both interpretation of standards and appraisal methods still differ considerably between markets (Crosby et al., 2011).

Therefore, alternative approaches to tracking real estate performance might seem desirable. One option may be to monitor the share prices of listed real estate companies. Such prices are frequently and easily observed, they are set by trading activity, and procedures exist to adjust returns for the 
effects of corporate borrowing. However, an investment in listed real estate differs in character from direct ownership of properties as the trading environments are dissimilar, different types of investor participate and the companies concerned may engage in a wider range of activities than real estate investment. Nonetheless, there is evidence that listed real estate returns are linked to those of the underlying real estate market in the long run (see Hoesli \& Oikarinen, 2012).

Another option is to create transaction based series using econometric procedures to control for variations in the quality and timing of commercial real estate transactions. Yet obtaining data at an adequate level of detail for some methods is problematic and, without sufficient observations, the resulting indices may exhibit excessive noise. Another concern is whether properties that are traded are representative of their market in terms of their characteristics and price trends, either generally or during specific phases of the real estate cycle. Nonetheless, there have been many efforts to estimate transaction based indices in the academic literature as well as recent efforts by commercial data providers to produce such series for the US and other real estate markets.

One such initiative has been the release of 'Transaction Linked Indices' by Investment Property Databank (IPD). These have been produced for several European real estate investment markets and it is these indices that are the focus of this paper. The paper has two main objectives. The first is to explain in detail the way in which these indices are constructed given their reliance on econometric models and a mass appraisal process. The second objective is then to compare these series with the appraisal based indices that currently exist in those markets. In light of the discussion above, the key question is whether these transaction based series provide different insights as to the returns from and risks of commercial real estate investments in Europe.

The remainder of the paper is structured as follows. In the next section, the method that is used to construct these transaction based series is explained and the literature that explores this method is reviewed. The third section then discusses how the method was implemented with a focus on the nature of the dataset that is held by IPD, which is also used to create their appraisal based series in the countries concerned. The fourth section considers the results from the econometric models and then compares the capital returns reported by the two types of indices over Q1 2002 to Q4 2012. This period is of particular interest given the major real estate cycle that occurred in most European real estate markets during this period. A final section then offers concluding reflections.

\section{Discussion of methods}

The methods used to construct appraisal based indices are fairly well established. To try and control for differences in quality over a particular measurement period, they analyse the change in value of a held (non-traded) sample of properties for which appraisal inputs are recorded at both the start and the end of the period concerned. These inputs should represent fresh external appraisals of asset value that are relevant to the dates in question [2]. At the end of the period, the change in value can then be chain-linked with measurements for earlier and later periods to create a longer series. For instance, the formula that is used by IPD (2012) to calculate a single period capital return (analogous to price change) is as follows: 


$$
\mathrm{CR}_{\mathrm{t}}=\left(\frac{\mathrm{CV}_{\mathrm{t}}-\mathrm{CV}_{\mathrm{t}-1}-\mathrm{CX}_{\mathrm{t}}+\mathrm{CI}_{\mathrm{t}}}{\mathrm{CV}_{\mathrm{t}-1}+\mathrm{CX}_{\mathrm{t}}}\right) \times 100
$$

Where $\mathrm{CR}_{\mathrm{t}} \quad$ is the capital return over the period concerned;

$\mathrm{CV}$ is the capital value at the end of a period;

$\mathrm{CX}_{\mathrm{t}} \quad$ relates to capital expenditure over the period; and

$\mathrm{Cl}_{\mathrm{t}} \quad$ relates to capital receipts received over the period.

This formula is applied to sets of assets by summing values, receipts and expenditures for all the assets concerned prior to its computation. Information on income and minor expenditures is usually collected, too, so that income and total return measures can be produced.

The methods used to create transaction based series are more complex. As the sample of traded assets changes from period to period, it is necessary to control for differences in the nature of those samples over time. Otherwise, measured changes in price could simply reflect fluctuations in quality. Hedonic regression techniques explicitly model the effects of different attributes on product prices and thus allow them to be controlled for during index construction. A hedonic regression typically takes the following form:

$$
\ln P=\beta_{0}+\beta_{1} X_{1}+\beta_{2} X_{2} \ldots+\beta_{n} X_{n}+\varepsilon
$$

Where $P \quad$ is the sale price of a product,

$X_{n} \quad$ represent $n$ characteristics of that product,

$\beta_{\mathrm{n}} \quad$ are coefficients that capture the price impact of each characteristic and

$\varepsilon \quad$ equals a random error term.

Equation (2) can be applied period by period or to pooled transaction data if time dummies are added. An index can then be derived by using the coefficients to predict the price of a representative asset or to predict the price of a set of unsold properties. However, there are issues with the hedonic approach that include difficulties in identifying all relevant influences on price and choosing the right functional form (Shiller, 1993). In addition, there is the problem of gaining sufficient and adequate data on asset attributes from available data sources. Yet if important factors are excluded from equation (2), this can lead to bias in the coefficients and the indices unless the omitted factors are orthogonal to the variables that are included in the model.

An alternative approach, proposed by Clapp (1990), underlies the Transaction Linked Indices that are discussed here. Clapp sought to analyse land prices, but the information for his study area lacked details on the attributes of the land being traded. However, appraisal based values for the land parcels were available, these being estimated periodically for tax assessment purposes. Clapp argued that these could be substituted for the attribute variables required by equation (2), since just as differences in characteristics reflect quality variations between assets, differences in appraisals at a specific time also reflect such variations. This is because appraisers take into account the physical and location attributes of each property when forming judgements about value. Therefore, if appraisals (denoted $A$ ) are available to substitute in place of characteristics, the model to be estimated becomes:

$$
\ln \mathrm{P}=\beta_{0}+\beta_{1} \ln \mathrm{A}+\varepsilon
$$


As with a hedonic model, time dummies can be added or (3) can be estimated period-by-period if repeated sets of reference appraisals are available. This approach does not have the extensive data requirements of the hedonic model and so is more easily applied provided that appraisal inputs are available for the market of interest. Furthermore, appraisals may capture aspects of quality that are difficult to observe or measure within a hedonic framework (Fisher et al., 2003; Gatzlaff \& Holmes, 2013). Yet differences between assets will not be quantified perfectly, so the model being estimated can be written as:

$$
\ln \mathrm{P}=\beta_{0}+\beta_{1}(\ln \mathrm{A}-\mu)+\varepsilon
$$

Where $A$ equals the assessed value and

$\mu \quad$ is a random disturbance term that captures random error in assessment.

This highlights that the observed appraisal is only a proxy for the true (but unobserved) value of the bundle of attributes in each case. Both the appraisal and an element of error are incorporated into the regression and this reduces the precision with which quality can be controlled. Furthermore, the appraisal variable will be correlated with the error term, violating the assumptions under which OLS produces unbiased estimators. This can be shown through rearrangement of equation (4):

$$
\ln \mathrm{P}=\beta_{0}+\beta_{1} \ln \mathrm{A}+\left(\varepsilon-\beta_{1} \mu\right)
$$

One way to tackle this would be to use the instrumental variables technique. This involves finding another variable that is highly correlated with the problem variable, but not the error component of that variable. Both the instrument and problem variable are then used in the estimation strategy, leading, in principle, to more consistent estimators. However, there is a trade-off in terms of the variance of the resulting estimators, which increases, and this may be undesirable if the primary purpose of the model is to obtain predictions of price. Furthermore, analysis by Clapp \& Giaccotto (1992) suggests that, given certain conditions, the problem becomes negligible in large samples. Hence, subsequent studies that have used the assessed value approach have not tended to consider this problem further [3].

Systematic errors may exist between either prices and appraisals (because of timing differences) or appraisals and true market values (perhaps reflecting micro-level appraisal processes). If so, these will be captured by the $\beta$ coefficients. This would not prevent quality differences between properties at a given time from being represented effectively provided that the bias was consistent across the set of appraisals being used. If appraisals were systematically inconsistent in cross-section, though, this could be problematic. This might be so if a sample includes transactions from different regions or nations and appraisers in some places behave differently to appraisers in others. This motivates the inclusion of dummy variables for different areas or asset types in cases where transaction data must be pooled.

The assessed value approach is used by several studies to estimate transaction based commercial real estate indices, reflecting the nature of available data. Fisher et al. (2003) apply a variant of this method to sales recorded in the US National Council of Real Estate Investment Fiduciaries (NCREIF) database. Their proxy for missing hedonic information was the log of the purchase price per square foot for each property and they included dummies for property types and regions. Fisher et al. (2007) then use the same database and a more refined model where the log of appraised value per 
square foot is used as the hedonic proxy. In both cases, transaction based series were more volatile and less autocorrelated than comparable appraisal based indices while changes led those in the appraisal indices over the periods studied. Gatzlaff \& Holmes (2013) have applied the assessed value approach to commercial property tax records for Florida.

Devaney \& Martinez Diaz (2011) applied the approach to UK commercial real estate data held by IPD. Like Fisher et al. (2007), they use appraisals as a hedonic proxy, but their study differs in that separate models are estimated for each time interval rather than a single model for the entire time frame covered by the data. Furthermore, coefficients from these models are used to predict prices for all unsold assets in their dataset, enabling value weighted indices to be constructed. In common with US research, they found transaction indices to be more volatile and less autocorrelated than appraisal based comparators, but the authors did not find that these captured turning points earlier. They suggest that this reflects limitations with their sales data and approach.

Some of the studies recognise that sample selection effects may be present in their data. Sample selection concerns the interrelationship between asset characteristics and the behaviour of market participants over time in bidding for and accepting bids on properties, which affects the likelihood of different assets trading and the prices that will be observed. In essence, the assets that sell may give a distorted picture of price movements. Hence, Gatzlaff \& Haurin (1998) proposed the use of a twostep procedure developed by Heckman (1979) to test and correct for the existence of bias caused by sample selection effects. This is described in more detail by both Fisher et al. (2003) and Devaney \& Martinez Diaz (2011).

This procedure may be problematic if a dataset has only limited information on the factors that influence sale decisions at different times. This is likely to be true where use of hedonic modelling is ruled out owing to inadequate attribute data. Furthermore, findings from using this procedure with the assessed value approach are mixed with regard to its importance. Results in Fisher et al. (2003) suggest that selection bias has an important impact on index figures, but Fisher et al. (2007) found that it did not significantly affect their series. Devaney \& Martinez Diaz (2011) found that selection bias was time varying; its effects appear to be stronger during downturns in commercial real estate markets. As a result, their selection corrected index behaves more plausibly than an uncorrected series during the downturn covered by their study.

At present, Transaction Linked Indices for European real estate markets are generated from OLS estimations of an expanded version of equation (3). The model, which is set out further in the next section, is estimated on a quarter by quarter basis using a dataset that includes transactions from a number of countries. It is not preceded by tests for sample selection bias. Two-step models were tested on this dataset, but their parameters were highly unstable and this stems from small and sharply fluctuating numbers of transactions for some countries and asset types in both absolute terms and relative to the number of unsold assets. It is noted that the absence of a correction for selection bias is an important limitation of the series that follow.

\section{Data and implementation}

The data used in this study are drawn from the databases of Investment Property Databank (IPD) who provide performance measurement services for real estate investors in over 20 countries. At 
the end of 2012, their databases contained information on $€ 580$ billion of direct real estate assets in Europe [4]. These assets are owned primarily by investment institutions such as insurance companies, pension funds, open-ended funds, publicly listed property companies and REITs. As such, the data represent investment grade real estate in different countries, but the coverage of the real estate investment market in different countries varies, as indicated by Table 1. Nonetheless, in terms of scale and scope, the data source is one of the best available for studying international real estate markets.

\section{INSERT TABLE 1 AROUND HERE}

The IPD databases consist of appraisals and cash flow information for individual properties, which are then used to measure the investment returns achieved by real estate portfolios. The appraisals are usually externally conducted assessments of the Market Value of individual assets as at the date of valuation. This information is used to generate appraisal based indices, the frequencies of which are dependent on the underlying appraisal regimes that contributing funds have adopted. It can be seen from Table 1 that this frequency is annual in most European real estate markets. This, together with the relatively recent creation of performance measurement services in many cases, means that time series data on returns for many direct real estate markets is limited.

One way to address the limited frequency of these series is to use interpolation techniques with reference to another source of performance information or a pre-determined process such as linear interpolation. However, as an appraisal is required at both the start and end of each year in order to interpolate intervening values, this cannot increase the speed of reporting and the resulting series are highly smoothed. Nonetheless, to provide quarterly comparators for what follows, interpolation was applied by IPD for the countries without appraisals at a quarterly frequency. Another option is to adopt a transaction based method, using information on sales throughout the year. Given the availability of prior appraisals and only a limited number of attribute variables in the IPD databases, the assessed value approach was selected to generate new transaction based indices for European real estate markets.

Data for all countries listed in Table 1 except Finland and the UK are used to estimate a Europewide regression model, which is set out below. The UK data is used in a similar, but country-specific model that is discussed by Devaney \& Martinez Diaz (2011). From the Europe-wide model, separate indices are produced for Denmark, France, Germany, Ireland, the Netherlands, Norway and Sweden. This is done by extracting relevant information from estimation of the model and using it to predict prices for unsold assets in those countries - a process that is outlined further in the text that follows. These countries were selected based on the size or length of the dataset in each case. A Southern Europe series was also constructed using data for Italy, Portugal and Spain [5]. Finally, Eurozone and Pan-European aggregates were produced by weighting results for individual countries according to estimates of market size.

Indices were estimated for Q4 2001 to Q4 2012 and this is guided by when records start for most countries, though some have been monitored by IPD for a longer period. Table 2 shows the number of sales per year for each market that could be used in the price models. This is not equal to the total number of sales recorded by IPD because filters are applied to remove outliers. For instance, sold 
properties must have been held by their owner for at least six months prior to the quarter of sale, so that prior appraisals are available, while their value or sale price should not be less than $€ 12,500$ or above $€ 1$ billion. Cases are also excluded where the mark up on prior appraisal lies outside the range $-50 \%$ to $+50 \%$, so that these sales do not distort estimations.

\section{INSERT TABLE 2 AROUND HERE}

\section{INSERT TABLE 3 AROUND HERE}

In Table 2, differences in sale counts between countries and time periods will reflect differences in market size and activity, plus changes in database composition and coverage. Overall, the number of sales per year peaked in $\mathbf{2 0 0 7}$ before falling in the wake of the global financial crisis and economic problems in the Eurozone. This is broadly consistent with the patterns in capital flows discussed in Newell et al. (2010), except that the fall in activity seems more gradual in this sample of investors. However, some countries such as Norway and Sweden exhibit increases in sales in 2008, but these examples are also consistent with patterns identified by Newell et al. (2010).

Meanwhile, figures in Table 3 indicate that several countries had at least one quarter where no sales were recorded. Therefore, the regression model for each quarter has been estimated using the sales completed in that quarter and sales completed in the preceding quarter (i.e. a six month rolling sample of sales). For example, for Q4 2012, the model utilises sales occurring from July to December of that year to get a transaction based estimate of market movement. This temporal aggregation of transaction evidence is far from ideal, but has been applied to reduce estimation noise and ensure that certain markets are always represented in the models. Note that this approach was not adopted when constructing the UK series owing to a greater volume of evidence here on a quarter-to-quarter basis.

The dataset does record some asset attributes, such as asset type and size and this enables both the country where an asset is located to be identified and the sector of the market (office, industrial, retail or residential) to which each property belongs, with residential being an important part of the property investment market in several of the countries studied [6]. Intercept dummies for sectors were added to the basic price model in order to test and distinguish differences in pricing between them. Dummy variables were also used to identify countries and these enable the separate national indices to be constructed [7]. Thus, the price model estimated for each quarter for the European dataset is:

$$
\ln \mathrm{P}=\beta_{0}+\beta_{1} \ln \mathrm{A}+\sum \delta_{\mathrm{j}} \mathrm{C}_{\mathrm{i}, \mathrm{j}}+\sum \lambda_{\mathrm{k}} \mathrm{S}_{\mathrm{i}, \mathrm{k}}+\varepsilon
$$

Where $P \quad$ equals the sale price in Euros

A is the appraised capital value in Euros for two quarters prior to sale

$\mathrm{C}_{\mathrm{j}} \quad$ are $0 / 1$ dummy variables for $\mathrm{j}$ countries

$S_{k} \quad$ are $0 / 1$ dummy variables for $k$ sectors of the real estate market

$\varepsilon \quad$ is a random error term 
The data used in the models is denominated in Euros, regardless of whether or not a country is in the Eurozone. This should not affect the relativity between price and value for each building and it ensures that inputs are consistently scaled. For non-Eurozone countries, after the other steps below are completed, the indices are converted into local currency terms. As in Fisher et al. (2007) and Devaney \& Martinez Diaz (2011), the appraisals used for the hedonic proxy are not those for the quarter end immediately before sale, but those for the preceding quarter end and this is to try and ensure that the appraisal is independent of the price. For instance, if an appraiser became aware of negotiations surrounding a sale, the amount under discussion may influence the appraisal that is produced for that property.

Using coefficients from the estimation of (6), an index may be derived in two ways. One way is to specify one or more 'typical' assets, e.g. a German office building of a particular value, and to predict what it would have sold for in each quarter using $\beta_{0}, \beta_{1}$ and the coefficients for the relevant country and sector terms [8]. The set of values then form an index of how that type of property performed over time. Another way is to predict prices for a set of buildings, such as those in the IPD database that did not sell in that quarter, and track how the total value for that set of buildings changes from period to period. The second approach is adopted here to ensure that the indices are weighted in a similar way to the appraisal based indices for these markets, i.e. taking account of the relative value of different assets and the contribution of different sectors and locations.

Hence, the approach is a mass appraisal process that utilises transaction evidence in a statistical manner, not through traditional appraisal techniques. It is implemented in the following way. In a given quarter, assets that did not trade in that quarter in all the countries included in the model are identified. Coefficients from the regression estimated for the preceding quarter are then used to predict a start (In) price for this set of assets. Next, coefficients from the regression for the current quarter are used to predict end (In) prices for this sample. The predicted log prices are then exponentiated, but, since this is known to provide biased predictions of cash prices, these values are adjusted subsequently in the manner recommended by Miller (1984):

$$
\hat{\mathrm{P}}=\exp (\ln \hat{\mathrm{P}}) \times \exp \left(\hat{\sigma}^{2} / 2\right)
$$

Here, $\sigma^{2}$ is the Mean Squared Error of the regression that generated the predicted In price.

For a specified set of properties, such as those for a particular country, estimated start and end prices for each quarter are then summed and the change between these totals is computed. The percentage change is then a value-weighted capital return rate that may be chain-linked with other such return rates into a longer series where samples for individual intervals remain constant, but are permitted to change between intervals as the composition of the real estate market changes over time. However, unlike the appraisal based capital return indices produced by IPD, these series do not take into account capital expenditure or capital receipts [9]. This is one inconsistency in a process that otherwise seeks to be consistent in calculation and segment representation once predicted price inputs have been created.

\section{Results}


The first set of results to consider are the coefficients for the price models that are estimated in each quarter. Selected coefficients and tests for models up to Q4 2012 are shown in Table 4. The constant $\left(\beta_{0}\right)$ and the coefficient for the logged appraisal variable $\left(\beta_{1}\right)$ provide measures of systematic bias in appraisals relative to prices. $\beta_{0}$ captures any bias that is consistent across assets regardless of their value while $\beta_{1}$ captures variation between high and low value assets. However, interpretation of $\beta_{0}$ is complicated by the use in the model of intercept dummies for different countries and sectors. Thus, in isolation, it only captures bias in terms of the base groups; these being France and offices for the country and sector dummies, respectively [10].

\section{INSERT TABLE 4 AROUND HERE}

The relevant tests for bias are whether a null hypothesis of equality with zero can be rejected in the case of the intercept and a null hypothesis of equality with one can be rejected for $\beta_{1}$. Table 4 shows that $\beta_{0}$ is only significantly different from zero at the $5 \%$ level on 13 out of 45 occasions during this period, despite the inbuilt time gap between appraisal and transaction dates that arises from the research design. It is notable, though, that eight of those occasions are during the years 2007 to 2010 when the real estate cycle in most countries moved from boom to downturn. Meanwhile, $\beta_{1}$ varies significantly from unity at the $5 \%$ level on only 11 out of 45 occasions. Again, eight of those occasions are in the years 2007 to 2010.

Tests for joint significance of the country dummies and similar tests for the sector dummies are reported on the right of Table 4. These tests detect whether the relationship between prices and appraisals varies systematically between the countries or property types included in the model. The country dummies are jointly significant at the $5 \%$ level in 34 out of 45 quarters and are important in practical terms for identifying different price trends between nations. The sector dummies are jointly significant at the $5 \%$ level on 27 out of 45 occasions. These results appear to support the inclusion of additional dummy variables in order to capture pricing differences between different property types and areas.

Table 5 contains summary statistics for the period Q4 2001 to Q4 2012 for indices produced using the coefficients and mass appraisal procedure described earlier. UK results from the OLS approach outlined in Devaney \& Martinez Diaz (2011) are shown as well for comparison. The same statistics for appraisal based indices of each market are also shown. The latter include published IPD quarterly indices in the case of Ireland, the Netherlands and the UK and quarterly indices that have been derived using interpolation procedures in the case of other countries. The statistics shown are the average capital return rate (Panel A), the standard deviation in capital return rates (Panel B) and the first order autocorrelation in return rates (Panel C). The figures are for All Property indices and this should be borne in mind when comparing different countries, as the sector make-up of each country differs. This should not affect comparisons across different types of index for each country, though, as here the contributions of each sector will be similar.

\section{INSERT TABLE 5 AROUND HERE}


In principle, long run average returns shown by transaction based and appraisal based indices for each country should be the same, with the main influence of appraisal smoothing thought to be on the volatility and correlations of the latter. As can be seen from Panel A, there are mostly only minor differences in the average return rate shown by the two types of series, with Transaction Linked Indices showing slightly stronger growth over the period. Meanwhile, standard deviations for the transaction series are larger in all cases. They are typically 2 to 4 times higher than those measured from appraisal based returns, but Germany and the UK are outliers in this respect. For Germany, the ratio of 13 is driven by an extremely low standard deviation for its appraisal based series, which can be questioned in the light of continuing debate around German appraisal processes (see Crosby et al., 2011).

The other ratios are consistent with earlier research that tries to establish the 'true' volatility of real estate markets using desmoothing techniques. This research is reviewed by Geltner et al. (2003) who report that standard deviations increase by 1.5 to 5 times over those measured from appraisal based data when such procedures are implemented, depending on the techniques and data used. Panel $C$ then shows the extent to which current period return rates are related to those in the prior period. A value of zero indicates that returns in the immediate past have no predictive power for the present, which is suggestive of weak form efficiency. The appraisal based return rates exhibit high serial correlation and all of these correlations are significantly greater than zero at the $1 \%$ level. This is in contrast to the Transaction Linked Indices where first order autocorrelation figures are always lower and only significantly different from zero (at the $5 \%$ level) for the Netherlands and the UK.

The time series performance of the indices for different countries is shown visually by Figures 1 and 2. The former displays capital return series for countries in the Eurozone and the latter presents indices on a local currency basis for non-Eurozone real estate markets.

\section{INSERT FIGURE 1 AROUND HERE}

\section{INSERT FIGURE 2 AROUND HERE}

The charts demonstrate the consistency of the two types of series in terms of their overall trends and highlight the comparative smoothness of the appraisal based series in each case. Typically, the Transaction Linked Indices plot a plausible path through time, but some of the series shown in Figure 2 exhibit a saw-tooth profile in places that may be a product of estimation noise rather than genuine volatility [11]. It is also interesting that the transaction based series do not seem to lead when marking the peak of the cycle. However, they often display a more distinct trough in real estate prices than their appraisal based counterparts whilst the magnitude of the rise and fall in each case tends to be greater. The exception here is Germany where no clear cycle in either of the direct real estate series is evident.

These comparisons are complicated by the fact that interpolation has been applied by IPD in some cases to create the quarterly appraisal based series [12]. For example, if a market peaks in Q1 2008, but the appraisals for contributing investors are only conducted at each calendar year end, an appraisal based index for that market may misreport the peak as either Q4 2007 or Q4 2008 under linear interpolation approaches. Therefore, in Table 6, a comparison of peak and trough points is 
only presented for countries where the appraisal indices rely on genuine quarterly valuation inputs. Panel A shows that peaks in the Transaction Linked Indices occur in the same or an adjacent quarter to those in the appraisal based series. In Panel B, though, only the UK has a trough appearing in both direct market measures, this occurring in Q2 2009 in both cases.

\section{INSERT TABLE 6 AROUND HERE}

The evidence in the table shows that the turning points in the Transaction Linked Indices are not always ahead of those shown by appraisal based indices. This finding runs counter to expectations given the literature on issues with appraisals that was discussed earlier in this paper. The temporal aggregation of sales evidence during the modelling phase is a possible explanation for these results. However, the nature of such aggregation is more limited in the case of the UK, where regressions are conducted on sales gathered from a single quarter rather than two quarters as per the approach used here for other European markets. Therefore, this explanation does not fit the results observed in the table.

Another explanation relates to the fact that the timing of each sale has been based on its formal completion date. Crosby \& McAllister (2004) note that price agreement typically occurs prior to the formal completion of a transaction and they find the median time between these points to be c. 80 days for a sample of UK sales, i.e. just under three months. Oikarinen et al. (2013) in their analysis of public and private real estate returns cite expert opinions on the length of this time gap to justify lagging the transaction indices they use by one quarter. If this step were repeated here for the UK Transaction Linked Index, the difference in marking the peak of the market would be removed and it would lead the appraisal based index in terms of marking the market trough.

Yet several factors inhibit a simple adjustment. First, Crosby \& McAllister (2004) document a large dispersion and skewed distribution in individual transaction times [13]. Second, research by Scofield (2013) found that time to transact was time-varying, with more rapid times to completion during the boom phase of the UK real estate cycle. These findings suggest that transaction level adjustments would be more accurate, but these were not possible as price agreement date was not recorded in the dataset. Third, information on transaction times and stages for other European markets was not available. Since negotiation and due diligence processes for property transactions will differ between countries, it would not be safe to use an adjustment based on UK evidence. This is a topic that would benefit from further research.

\section{Conclusions}

This study examines Transaction Linked Indices that have been estimated for several European real estate markets using IPD data on sales of investment grade real estate. Its objectives were to explain in detail how these indices are constructed and to establish whether they provide new information about returns, risk and turning points in these markets when compared to that from appraisal based series. The Transaction Linked Indices are constructed using the assessed value method proposed by Clapp (1990) and recently applied to US real estate by Fisher et al. (2007) and UK data by Devaney \& Martinez Diaz (2011). Value-weighted series are produced for each market using a mass appraisal 
process that is based on output from an econometric model of sale prices that is estimated for each quarter of the study period.

The indices provide additional evidence on the performance of European real estate investments over the period Q4 2001 to Q4 2012, which encompasses a major cycle both in real estate values and the wider economies. In terms of long run average return, the rates indicated by the Transaction Linked Indices are similar, though slightly higher, than those shown by appraisal based comparators. However, the intervening rise and fall was usually greater, suggesting a more pronounced cycle. The Transaction Linked Indices also exhibited higher volatility, with the standard deviation in capital return rates being around two to four times larger than that produced from corresponding appraisal based series. These increases in volatility are consistent with the findings from studies that apply desmoothing techniques to appraisal based data.

The Transaction Linked Indices have some limitations. First, they were not markedly faster than appraisal indices in marking either the peak or trough of the real estate cycle in different countries. This may reflect their reliance on sale completion dates to determine the date of a price observation, which is a potential source of lagging in the transaction based indices generated by the nature of the underlying data. Second, it is difficult to produce plausible series below country level owing to the relatively low number of sales for each country that are available each quarter. Third, for the same reason, it was difficult to test and correct adequately for sample selection bias. Such corrections are usually absent from other transaction based indices based on deal-driven rather than performance measurement databases.

These issues limit the utility of Transaction Linked Indices as barometers of values for different markets and prevent their use in applications that need detail and continuity at disaggregate levels, such as benchmarking. However, the potential for these indices to be produced on a quarterly basis for markets with annual appraisal regimes offers a practical advantage for understanding trends on a timelier basis. This is because sales evidence can be used as it occurs rather than needing to wait for a year-end valuation. They also may be of value owing to the estimates they provide of the volatility of real estate investment markets at an aggregate level. Such figures could be used to inform risk modelling and asset allocation since they provide an alternative estimate of risk to appraisal based series or de-smoothed variants of such series.

\section{Notes}

[1] Some studies debate this point. For example, analysis by Edelstein \& Quan (2006) suggests that this may not hold, although they do find evidence for smoothing in their empirical work.

[2] In some instances, index producers have rolled forward appraisals from earlier periods or have interpolated values between two externally provided appraisals. The former case is known as the stale appraisal problem and has been a feature of indices produced by the National Council of Real Estate Investment Fiduciaries (NCREIF) in the United States (see Geltner \& Goetzmann, 2000). 
[3] An exception is Devaney \& Martinez Diaz (2011). They report that IV-based estimates produced indices for the UK that were near identical to ones derived from OLS models, though the results were not presented.

[4] IPD, personal communication.

[5] Separate indices could not be constructed for these countries owing to small, variable samples of sales. In particular, there is an extreme drop in the number of sales for Portugal and Spain from 2008 onwards.

[6] Residential real estate investments only made up a significant fraction (20-40\%) of sales in the following countries: Austria, Denmark, France, Germany, Netherlands, Spain and Sweden. In Switzerland, residential sales actually predominate, making up c. $70 \%$ of the sales data. This is broadly in line with the representation of residential assets in the main datasets.

[7] In principle, slope dummies could be added to test for further differences in pricing behaviour, but experiments were not successful in terms of producing stable and useable models.

[8] As there are no time dummies in (6), the property value in each quarter could not be a fixed figure. It would need to change from period to period in line with movements in the appraisal based index to provide an updated assessment of the figure that the typical reference appraisal for such a property would have reached.

[9] Note that major capital expenditure within a period would cause a property to be classed as a development by IPD, not an investment, in which case it would not enter the dataset used here.

[10] However, using the coefficients for the dummy variables (the $\delta_{\mathrm{j}}$ in equation 6 ), parameters relevant to other sectors and countries may be computed and tested.

[11] Table 5 shows negative first order autocorrelation coefficients for Norway and Sweden that could be another signal of excessive estimation noise in these cases.

[12] This is not currently standard practice for their published indices.

[13] See Bond et al. (2007) for further analysis of the distribution of transaction times and the implications of this for real estate investors. 


\section{References}

Bond, S., Hwang, S., Lin, Z. and Vandell, K. D. (2007), "Marketing Period Risk in a Portfolio Context: Theory and Empirical Estimates from the UK Commercial Real Estate Market", Journal of Real Estate Finance and Economics, Vol. 34 No. 4, pp. 447-461.

Clapp, J. M. (1990), "A methodology for constructing vacant land price indices", Journal of the American Real Estate and Urban Economics Association, Vol. 18 No. 3, pp. 274-293.

Clapp, J. M. and Giaccotto, C. (1992), "Estimating Price Indices for Residential Property: A Comparison of Repeat Sales and Assessed Value Methods", Journal of the American Statistical Association, Vol. 87 No. 418, pp. 300-306.

Clayton, J., Geltner, D. and Hamilton, S. W. (2001), "Smoothing in Commercial Property Valuations: Evidence from Individual Appraisals", Real Estate Economics, Vol. 29 No. 3, pp. 337-360.

Crosby, N., Devaney, S. and Law, V. (2011), "Benchmarking and valuation issues in measuring depreciation for European office markets", Journal of European Real Estate Research, Vol. 4 No. 1, pp. 7-28.

Crosby, N. and McAllister, P. (2004), "Deconstructing the Transaction Process: An Analysis of Fund Transaction Data", Working Paper Two in IPF (2004), Liquidity in Commercial Property Markets, Investment Property Forum, London.

Devaney, S. and Martinez Diaz, R. (2011), "Transaction based indices for the UK commercial real estate market: an exploration using IPD transaction data", Journal of Property Research, Vol. 28 No. 4, pp. 269-289.

Edelstein, R. H. and Quan, D. C. (2006), "How Does Appraisal Smoothing Bias Real Estate Returns Measurement?", Journal of Real Estate Finance and Economics, Vol. 32 No. 1, pp. 41-60.

Fisher, J., Gatzlaff, D., Geltner, D. and Haurin, D. (2003), "Controlling for the Impact of Variable Liquidity in Commercial Real Estate Price Indices", Real Estate Economics, Vol. 31 No. 2, pp. 269303.

Fisher, J., Geltner, D. and Pollakowski, H. (2007), "A Quarterly Transactions-based Index of Institutional Real Estate Investment Performance and Movements in Supply and Demand", Journal of Real Estate Finance and Economics, Vol. 34 No. 1, pp. 5-33.

Gatzlaff, D. H. and Haurin, D. R. (1998), "Sample Selection and Biases in Local House Value Indices", Journal of Urban Economics, Vol. 43 No. 2, pp. 199-222.

Gatzlaff, D. and Holmes, C. (2013), “Estimating Transaction-Based Price Indices of Local Commercial Real Estate Markets Using Public Assessment Data", Journal of Real Estate Finance and Economics, Vol. 46 No. 2, pp. 260-281.

Geltner, D. and Goetzmann, W. (2000), "Two Decades of Commercial Property Returns: A RepeatedMeasures Regression-Based Version of the NCREIF Index", Journal of Real Estate Finance and Economics, Vol. 21 No. 1, pp. 5-21. 
Geltner, D., MacGregor, B. D. and Schwann, G. M. (2003), "Appraisal Smoothing and Price Discovery in Real Estate Markets", Urban Studies, Vol. 40 No. 5/6, pp. 1047-1064.

Heckman, J. J. (1979), "Sample Selection Bias as a Specification Error", Econometrica, Vol. 47 No. 1, pp. 153-161.

Hoesli, M. and Oikarinen, E. (2012), "Are REITs real estate? Evidence from international sector level data", Journal of International Money and Finance, Vol. 31 No. 7, pp. 1823-1850.

IPD (2012), IPD Index Guide: Edition Eight, Investment Property Databank, London.

Miller, D. M. (1984), "Reducing Transformation Bias in Curve Fitting", The American Statistician, Vol. 38 No. 2, pp. 124-126.

Newell, G., Adair, A. and McGreal, S. (2010), "Robustness of capital flows into the European commercial property markets during the global financial crisis", Journal of European Real Estate Research, Vol. 3 No. 3, pp. 182-202.

Oikarinen, E., Hoesli, M. and Serrano, C. (2013), "Do public real estate returns really lead private returns?", in Proceedings of the $20^{\text {th }}$ Annual Conference of the European Real Estate Society, Vienna, pp. 189-218.

Scofield, D. (2013), "Time to completion liquidity in UK commercial real estate investment: 20002008", Journal of European Real Estate Research, Vol. 6 No. 1, pp. 34-47.

Shiller, R. J. (1993), Macro Markets: Creating Institutions for Managing Society's Largest Economic Risks, Clarendon Lectures in Economics, Oxford University Press, Oxford. 
Table 1: IPD database size, market coverage and index frequency at end 2012 - Europe

\begin{tabular}{|c|c|c|c|c|c|}
\hline Country & $\begin{array}{l}\text { Number of } \\
\text { properties }^{1}\end{array}$ & $\begin{array}{l}\text { Capital value } \\
\qquad(€ \text { bn })^{1}\end{array}$ & $\begin{array}{l}\text { Est. market } \\
\text { size }(€ b n)^{1}\end{array}$ & $\begin{array}{l}\text { IPD coverage } \\
(\%)^{1}\end{array}$ & $\begin{array}{l}\text { Frequency of } \\
\text { appraisal index }\end{array}$ \\
\hline Austria & 595 & 7.1 & 26.1 & 27.3 & Annual \\
\hline Belgium $^{2}$ & 373 & 8.2 & 41.9 & 19.5 & Annual \\
\hline Czech Rep ${ }^{2}$ & 115 & 2.8 & 11.5 & 24.7 & Annual \\
\hline Denmark & 995 & 15.3 & 33.6 & 45.4 & Annual \\
\hline France & 6,190 & 97.8 & 240.6 & 40.7 & Annual, Biannual \\
\hline Finland $(\mathrm{KTI})^{3}$ & 2,356 & 21.8 & 45.7 & 47.7 & Annual \\
\hline Germany & 4,027 & 45.9 & 261.8 & 17.5 & Annual \\
\hline Hungary & 90 & 1.7 & 9.2 & 18.6 & Annual \\
\hline Ireland & 304 & 2.0 & 5.0 & 40.2 & Quarterly \\
\hline Italy & 1,946 & 26.5 & 76.2 & 34.7 & Annual, Biannual \\
\hline Netherlands & 4,521 & 37.3 & 114.7 & 32.5 & Annual, Quarterly \\
\hline Norway & 488 & 16.1 & 42.0 & 38.3 & Annual \\
\hline Poland $^{2}$ & 226 & 6.2 & 17.2 & 36.0 & Annual \\
\hline Portugal & 921 & 8.3 & 14.8 & 56.1 & Annual \\
\hline Spain & 554 & 16.4 & 37.7 & 43.4 & Annual \\
\hline Sweden & 1,482 & 33.1 & 120.4 & 27.5 & Annual \\
\hline Switzerland & 4,050 & 60.4 & 146.0 & 41.4 & Annual \\
\hline UK & 21,012 & 173.1 & 286.1 & 60.5 & Ann, Qtr, Monthly \\
\hline Eurozone & 21,787 & 271.2 & 864.6 & 31.4 & Annual \\
\hline Pan-Europe & 50,245 & 580.0 & $1,530.6$ & 37.9 & Annual \\
\hline
\end{tabular}

${ }^{1}$ Numbers are as reported by IPD and are subject to rounding.

${ }^{2}$ Indices have consultative status rather than full index status.

${ }^{3}$ The index for Finland is produced by KTI using procedures and methods that are consistent with those of IPD. 
Table 2: Number of transactions in each year that are available for modelling

\begin{tabular}{lccccccccccc}
\hline & 2002 & 2003 & 2004 & 2005 & 2006 & 2007 & 2008 & 2009 & 2010 & 2011 & 2012 \\
\hline Denmark & 76 & 104 & 127 & 124 & 127 & 87 & 82 & 23 & 15 & 9 & 41 \\
France & 292 & 341 & 283 & 314 & 392 & 484 & 480 & 464 & 440 & 328 & 281 \\
Germany & 275 & 218 & 229 & 213 & 472 & 416 & 246 & 98 & 151 & 201 & 122 \\
Ireland & 32 & 24 & 12 & 8 & 13 & 7 & 7 & 28 & 10 & 2 & 9 \\
Netherlands & 408 & 291 & 182 & 403 & 240 & 342 & 287 & 186 & 201 & 136 & 153 \\
Norway & 16 & 34 & 23 & 20 & 22 & 6 & 29 & 18 & 21 & 18 & 25 \\
Sweden & 295 & 328 & 120 & 104 & 44 & 118 & 209 & 66 & 85 & 73 & 134 \\
Southern Europe & 25 & 44 & 56 & 52 & 94 & 85 & 58 & 109 & 94 & 113 & 57 \\
\hline Retail & 294 & 245 & 179 & 231 & 333 & 261 & 390 & 227 & 312 & 231 & 277 \\
Office & 427 & 469 & 433 & 501 & 643 & 765 & 772 & 481 & 392 & 388 & 351 \\
Industrial & 136 & 83 & 93 & 114 & 106 & 136 & 94 & 131 & 86 & 143 & 108 \\
Residential & 567 & 640 & 396 & 534 & 449 & 521 & 317 & 375 & 389 & 330 & 220 \\
\hline Eurozone & 1,032 & 920 & 767 & 1,003 & 1,257 & 1,371 & 1,139 & 949 & 931 & 814 & 646 \\
Europe ex. UK & 1,424 & 1,437 & 1,101 & 1,380 & 1,531 & 1,683 & 1,573 & 1,214 & 1,179 & 1,092 & 956 \\
\hline
\end{tabular}

Note 1: This aggregation consists of Italy, Portugal and Spain.

Note 2: Includes additional transactions from Austria, Belgium, Czech Republic, Poland and Switzerland. 
Table 3: Number of transactions per quarter - summary statistics

\begin{tabular}{lccccccc}
\hline & Mean & Maximum & Minimum & Mean Q1 & Mean Q2 & Mean Q3 & Mean Q4 \\
\hline Denmark & 18.2 & 73 & 0 & 8.1 & 14.0 & 20.2 & 29.5 \\
France & 92.8 & 284 & 33 & 51.3 & 59.9 & 95.5 & 158.4 \\
Germany & 59.3 & 252 & 9 & 62.3 & 36.5 & 45.1 & 90.6 \\
Ireland & 3.6 & 16 & 0 & 2.8 & 4.5 & 2.0 & 4.8 \\
Netherlands & 67.2 & 218 & 11 & 35.9 & 56.5 & 52.2 & 119.6 \\
Norway & 5.2 & 29 & 0 & 5.5 & 3.9 & 4.2 & 7.1 \\
Sweden & 39.4 & 197 & 4 & 23.0 & 35.6 & 44.4 & 53.3 \\
Southern Europe & 17.6 & 46 & 2 & 13.5 & 18.4 & 15.0 & 22.9 \\
\hline Retail & 68.8 & 186 & 22 & 44.3 & 59.4 & 67.7 & 100.9 \\
Office & 128.1 & 337 & 51 & 94.7 & 99.1 & 125.0 & 188.0 \\
Industrial & 28.6 & 77 & 7 & 20.7 & 23.5 & 23.8 & 44.8 \\
Residential & 109.9 & 328 & 33 & 75.2 & 72.4 & 88.4 & 195.8 \\
\hline Eurozone & 247.6 & 622 & 94 & 173.7 & 180.1 & 215.2 & 407.0 \\
Europe ex. UK & 335.3 & 738 & 160 & 234.9 & 254.3 & 304.9 & 529.4 \\
\hline
\end{tabular}

Note 1: This aggregation consists of Italy, Portugal and Spain.

Note 2: Includes additional transactions from Austria, Belgium, Czech Republic, Poland and Switzerland. 
Table 4: Price model - selected coefficients and tests

\begin{tabular}{|c|c|c|c|c|c|c|c|c|c|c|}
\hline & $\mathrm{CON}$ & ANT & Prob. & & & Prob. & $\mathrm{COU}$ & ITRIES & & TORS \\
\hline & $\beta$ & s/e & $\beta=0$ & $\beta$ & s/e & $\beta=1$ & F-stat & P-value & F-stat & P-value \\
\hline Q1 2002 & -0.08 & 0.04 & 0.07 & 1.01 & 0.003 & 0.07 & 9.15 & 0.00 & 5.96 & 0.00 \\
\hline Q2 2002 & -0.07 & 0.04 & 0.10 & 1.01 & 0.003 & 0.03 & 1.95 & 0.07 & 0.84 & 0.47 \\
\hline Q3 2002 & 0.17 & 0.05 & 0.00 & 0.99 & 0.004 & 0.02 & 3.77 & 0.00 & 1.95 & 0.12 \\
\hline Q4 2002 & 0.15 & 0.06 & 0.01 & 0.99 & 0.004 & 0.05 & 3.38 & 0.00 & 3.38 & 0.02 \\
\hline Q1 2003 & -0.06 & 0.05 & 0.17 & 1.01 & 0.003 & 0.13 & 2.47 & 0.02 & 2.75 & 0.04 \\
\hline Q2 2003 & 0.04 & 0.05 & 0.42 & 1.00 & 0.003 & 0.51 & 2.82 & 0.00 & 1.95 & 0.12 \\
\hline Q3 2003 & 0.07 & 0.08 & 0.39 & 1.00 & 0.005 & 0.50 & 1.39 & 0.20 & 0.38 & 0.77 \\
\hline Q4 2003 & -0.04 & 0.06 & 0.47 & 1.00 & 0.004 & 0.48 & 1.72 & 0.09 & 1.96 & 0.12 \\
\hline Q1 2004 & -0.04 & 0.04 & 0.27 & 1.00 & 0.002 & 0.20 & 4.42 & 0.00 & 2.86 & 0.04 \\
\hline Q2 2004 & -0.04 & 0.04 & 0.37 & 1.00 & 0.003 & 0.34 & 5.33 & 0.00 & 5.48 & 0.00 \\
\hline Q3 2004 & 0.06 & 0.07 & 0.35 & 1.00 & 0.004 & 0.72 & 1.48 & 0.16 & 2.11 & 0.10 \\
\hline Q4 2004 & 0.07 & 0.06 & 0.22 & 1.00 & 0.004 & 0.47 & 0.49 & 0.86 & 2.61 & 0.05 \\
\hline Q1 2005 & -0.09 & 0.05 & 0.07 & 1.01 & 0.003 & 0.02 & 3.12 & 0.00 & 5.98 & 0.00 \\
\hline Q2 2005 & 0.00 & 0.05 & 0.98 & 1.00 & 0.003 & 0.66 & 3.71 & 0.00 & 3.62 & 0.01 \\
\hline Q3 2005 & 0.14 & 0.07 & 0.04 & 0.99 & 0.005 & 0.20 & 1.09 & 0.37 & 2.61 & 0.05 \\
\hline Q4 2005 & 0.12 & 0.06 & 0.04 & 1.00 & 0.004 & 0.38 & 6.30 & 0.00 & 2.66 & 0.05 \\
\hline Q1 2006 & -0.02 & 0.05 & 0.63 & 1.01 & 0.003 & 0.09 & 8.95 & 0.00 & 6.83 & 0.00 \\
\hline Q2 2006 & -0.07 & 0.06 & 0.25 & 1.01 & 0.004 & 0.13 & 2.47 & 0.01 & 5.61 & 0.00 \\
\hline Q3 2006 & -0.05 & 0.10 & 0.57 & 1.01 & 0.006 & 0.34 & 1.84 & 0.07 & 2.46 & 0.06 \\
\hline Q4 2006 & -0.02 & 0.08 & 0.79 & 1.01 & 0.005 & 0.08 & 4.28 & 0.00 & 6.50 & 0.00 \\
\hline Q1 2007 & 0.12 & 0.05 & 0.01 & 1.00 & 0.003 & 0.28 & 6.38 & 0.00 & 7.83 & 0.00 \\
\hline Q2 2007 & -0.04 & 0.05 & 0.47 & 1.01 & 0.003 & 0.16 & 3.61 & 0.00 & 25.21 & 0.00 \\
\hline Q3 2007 & -0.18 & 0.08 & 0.02 & 1.01 & 0.005 & 0.01 & 0.98 & 0.45 & 6.57 & 0.00 \\
\hline Q4 2007 & -0.16 & 0.07 & 0.02 & 1.01 & 0.004 & 0.00 & 1.89 & 0.07 & 1.90 & 0.13 \\
\hline Q1 2008 & -0.05 & 0.04 & 0.18 & 1.01 & 0.003 & 0.00 & 2.71 & 0.01 & 5.23 & 0.00 \\
\hline Q2 2008 & 0.05 & 0.04 & 0.21 & 1.00 & 0.003 & 0.56 & 3.05 & 0.00 & 3.05 & 0.03 \\
\hline Q3 2008 & 0.10 & 0.05 & 0.06 & 1.00 & 0.004 & 0.20 & 3.69 & 0.00 & 0.56 & 0.64 \\
\hline Q4 2008 & -0.05 & 0.05 & 0.31 & 1.00 & 0.004 & 0.24 & 12.29 & 0.00 & 4.65 & 0.00 \\
\hline Q1 2009 & 0.04 & 0.06 & 0.51 & 1.00 & 0.003 & 0.60 & 15.69 & 0.00 & 0.36 & 0.78 \\
\hline Q2 2009 & 0.16 & 0.06 & 0.01 & 0.99 & 0.004 & 0.01 & 15.39 & 0.00 & 5.49 & 0.00 \\
\hline Q3 2009 & 0.42 & 0.09 & 0.00 & 0.97 & 0.006 & 0.00 & 3.50 & 0.00 & 4.91 & 0.00 \\
\hline Q4 2009 & 0.17 & 0.06 & 0.01 & 0.99 & 0.004 & 0.00 & 7.84 & 0.00 & 0.60 & 0.62 \\
\hline Q1 2010 & 0.14 & 0.04 & 0.00 & 0.99 & 0.002 & 0.00 & 20.34 & 0.00 & 4.58 & 0.00 \\
\hline Q2 2010 & 0.17 & 0.04 & 0.00 & 0.99 & 0.003 & 0.00 & 15.91 & 0.00 & 1.61 & 0.19 \\
\hline Q3 2010 & 0.11 & 0.07 & 0.10 & 1.00 & 0.004 & 0.26 & 6.14 & 0.00 & 0.57 & 0.64 \\
\hline Q4 2010 & 0.03 & 0.06 & 0.62 & 1.00 & 0.004 & 0.83 & 11.25 & 0.00 & 0.96 & 0.41 \\
\hline Q1 2011 & 0.07 & 0.04 & 0.10 & 1.00 & 0.003 & 0.55 & 4.08 & 0.01 & 3.38 & 0.02 \\
\hline Q2 2011 & 0.02 & 0.04 & 0.66 & 1.00 & 0.003 & 0.88 & 6.36 & 0.00 & 13.95 & 0.00 \\
\hline Q3 2011 & -0.02 & 0.06 & 0.72 & 1.01 & 0.004 & 0.27 & 3.33 & 0.00 & 10.77 & 0.00 \\
\hline Q4 2011 & 0.00 & 0.06 & 0.97 & 1.00 & 0.004 & 0.37 & 4.35 & 0.00 & 1.30 & 0.27 \\
\hline Q1 2012 & 0.09 & 0.04 & 0.04 & 1.00 & 0.003 & 0.43 & 1.40 & 0.20 & 5.85 & 0.00 \\
\hline Q2 2012 & 0.06 & 0.05 & 0.18 & 1.00 & 0.003 & 0.85 & 1.52 & 0.16 & 7.99 & 0.00 \\
\hline Q3 2012 & 0.06 & 0.08 & 0.46 & 1.00 & 0.005 & 0.85 & 4.17 & 0.00 & 0.48 & 0.69 \\
\hline Q4 2012 & 0.13 & 0.08 & 0.08 & 0.99 & 0.005 & 0.33 & 3.67 & 0.00 & 4.19 & 0.01 \\
\hline
\end{tabular}


Table 5: Descriptive statistics for the quarterly capital return series: 2002-2011

\begin{tabular}{l|c|c|c}
\hline \multicolumn{2}{l}{ Panel A - Average quarterly capital return rate (\%) } \\
\hline & $\begin{array}{c}1 \\
\text { IPD Transaction Linked } \\
\text { Index }\end{array}$ & $\begin{array}{c}\text { IPD appraisal-based } \\
\text { index }\end{array}$ & $\begin{array}{c}\text { Difference } \\
\text { Denmark }\end{array}$ \\
France & 0.6 & 0.6 & 0.0 \\
Germany & 1.1 & 0.8 & 0.3 \\
Ireland & -0.3 & -0.4 & 0.1 \\
Netherlands & -1.2 & -1.4 & 0.1 \\
Norway & 0.2 & 0.2 & 0.0 \\
Sweden & 0.7 & 0.5 & 0.2 \\
Southern Europe & 0.6 & 0.4 & 0.3 \\
Eurozone & 0.5 & 0.1 & 0.4 \\
UK & 0.3 & 0.1 & 0.2 \\
\hline
\end{tabular}

Panel B - Standard deviation of capital return rates

\begin{tabular}{l|c|c|c}
\hline & $\begin{array}{c}\text { IPD Transaction Linked } \\
\text { Index }\end{array}$ & $\begin{array}{c}\text { IPD appraisal-based } \\
\text { index }\end{array}$ & Ratio TBI/VBI \\
\hline Denmark & 4.8 & 1.1 & 4.2 \\
France & 2.9 & 1.6 & 1.8 \\
Germany & 4.2 & 0.3 & 13.0 \\
Ireland & 9.1 & 5.2 & 1.8 \\
Netherlands & 2.2 & 1.1 & 1.9 \\
Norway & 7.0 & 1.5 & 4.7 \\
Sweden & 4.6 & 1.5 & 3.1 \\
Southern Europe & 4.7 & 1.1 & 4.3 \\
Eurozone & 2.5 & 0.8 & 3.3 \\
UK & 4.9 & 3.9 & 1.2 \\
\hline
\end{tabular}

Panel C - First order autocorrelation in return rates

\begin{tabular}{l|c|c|c}
\hline & $\begin{array}{c}\text { IPD Transaction Linked } \\
\text { Index }\end{array}$ & $\begin{array}{c}\text { IPD appraisal-based } \\
\text { index }\end{array}$ & \\
\hline Denmark & 0.05 & 0.88 & \\
France & 0.21 & 0.87 & \\
Germany & -0.03 & 0.84 & \\
Ireland & 0.22 & 0.87 & \\
Netherlands & 0.31 & 0.72 & \\
Norway & -0.11 & 0.81 & \\
Sweden & -0.22 & 0.84 & \\
Southern Europe & 0.21 & 0.91 & \\
Eurozone & 0.19 & 0.88 & 0.76 \\
UK & 0.47 & \\
\hline
\end{tabular}

Note 1: Geometric mean measured from Q4 2001. 
Table 6: Peak and trough points in the recent major real estate cycle

\begin{tabular}{l|c|c|c|c}
\hline \multirow{2}{*}{ Panel A - Timing and magnitude of index peak } \\
\cline { 2 - 5 } & \multicolumn{2}{|c|}{ IPD Transaction Linked Index } & \multicolumn{2}{c}{ IPD appraisal-based index } \\
\cline { 2 - 5 } & Quarter occurred & Rise from 2001.4 & Quarter occurred & Rise from 2001.4 \\
\hline \multirow{2}{*}{ Ireland } & 2007.2 & $113 \%$ & 2007.3 & $66 \%$ \\
Netherlands & 2008.3 & $32 \%$ & 2008.3 & $26 \%$ \\
UK & 2007.3 & $61 \%$ & 2007.2 & $53 \%$ \\
\hline
\end{tabular}

Panel B - Timing and magnitude of subsequent trough

\begin{tabular}{l|c|c|c|c}
\hline \multirow{2}{*}{} & \multicolumn{2}{|c|}{ IPD Transaction Linked Index } & \multicolumn{2}{c}{ IPD appraisal-based index } \\
\cline { 2 - 5 } & Quarter occurred & Change from peak & Quarter occurred & Change from peak \\
\hline Ireland & 2012.1 & $-73 \%$ & - & - \\
Netherlands & - & - & - & - \\
UK & 2009.2 & $-44 \%$ & 2009.2 & $-42 \%$ \\
\hline
\end{tabular}

Dash (-) indicates no clear peak or trough 
Figure 1: Comparison of capital returns series for each Eurozone market: 2002-2012

Indices track performance in local currency terms. Q4 $2005=100$.

(a) France

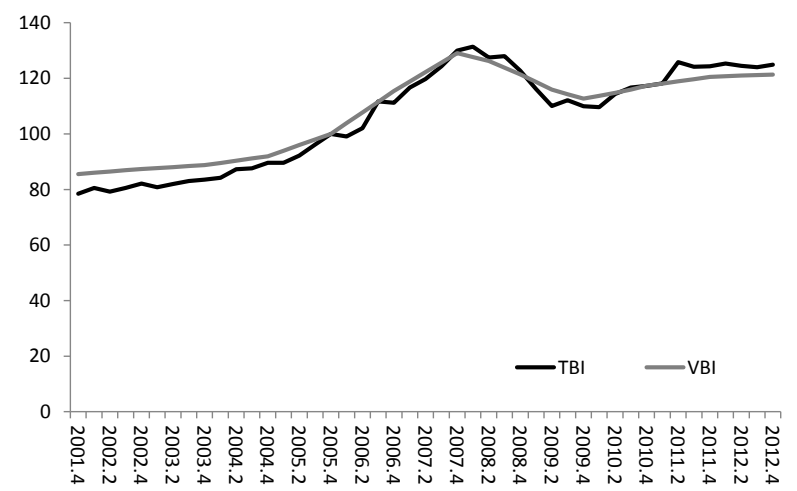

(c) Ireland

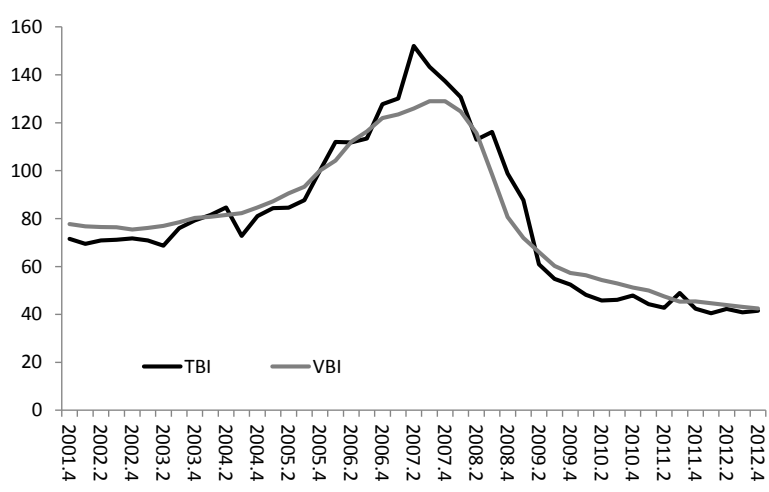

(e) Southern Europe

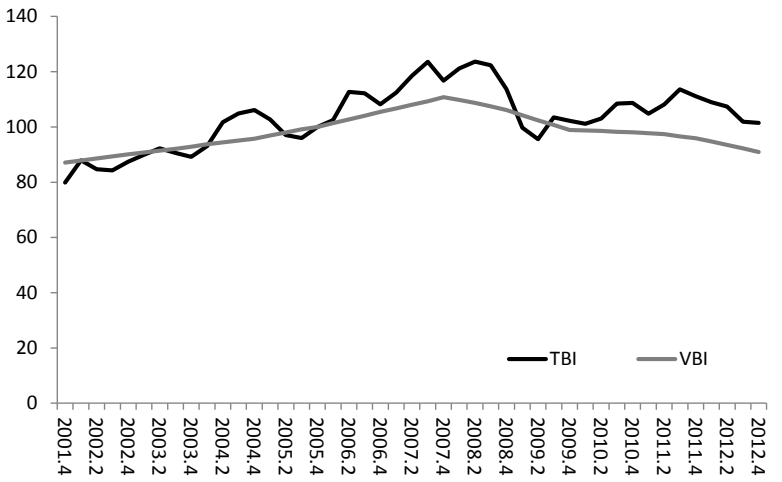

(b) Germany

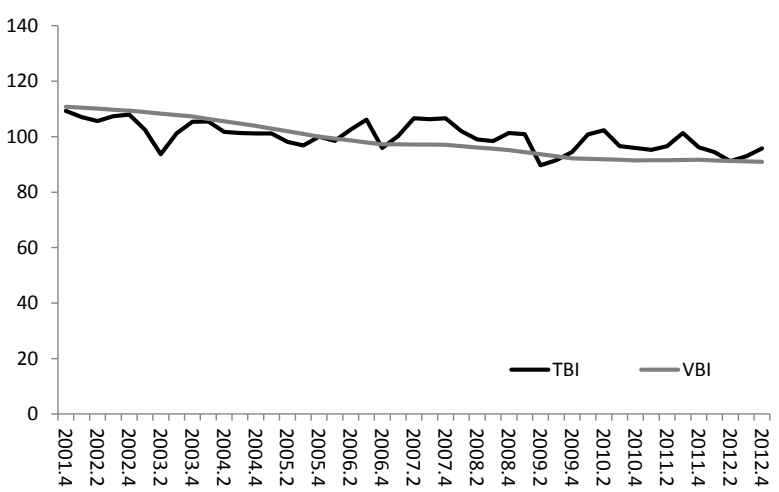

(d) Netherlands

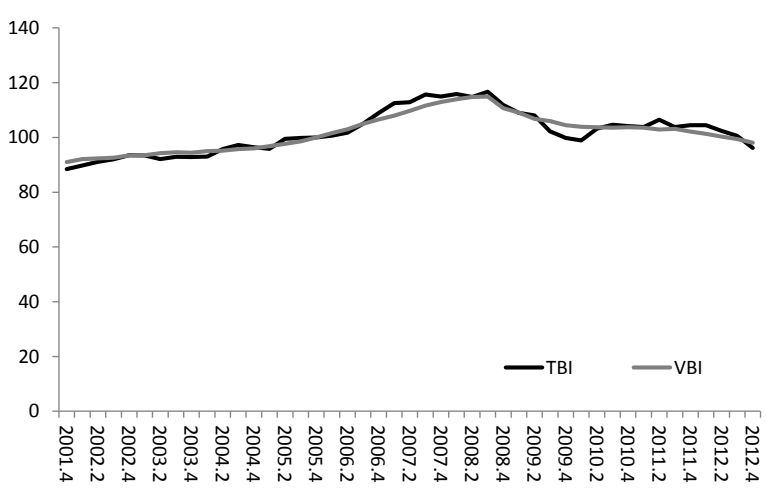

(f) Eurozone

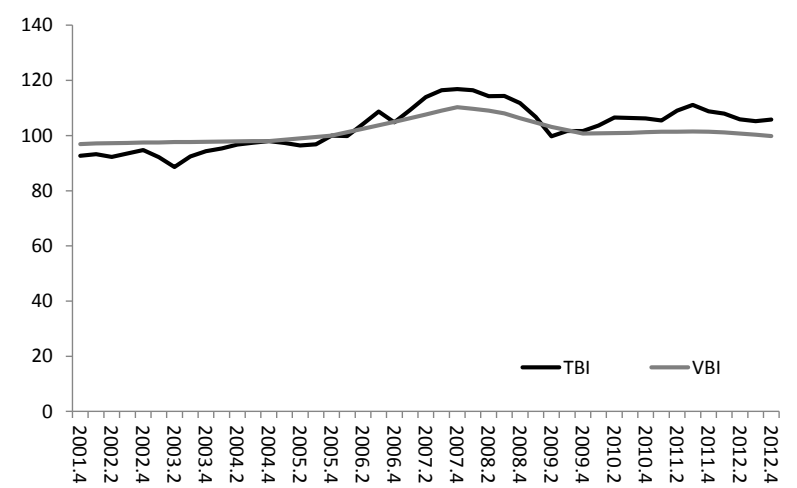


Figure 2: Comparison of capital returns series for non-Eurozone markets: 2002-2012

Indices track performance in local currency terms. Q4 $2005=100$.

(a) Denmark

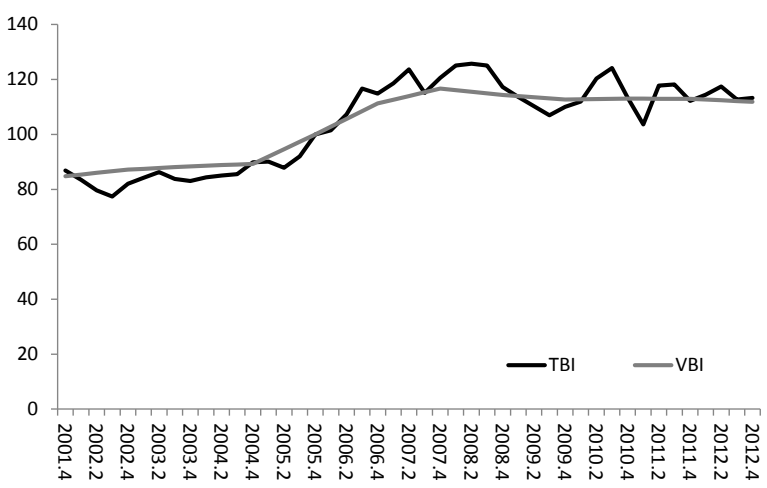

(c) Sweden

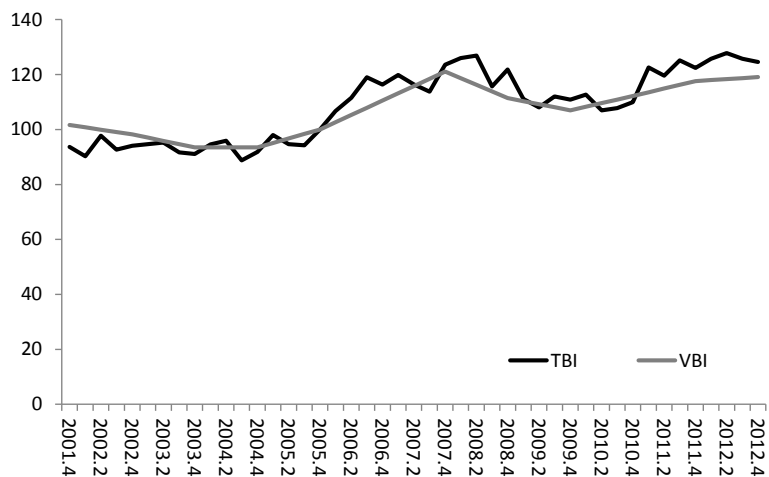

(b) Norway

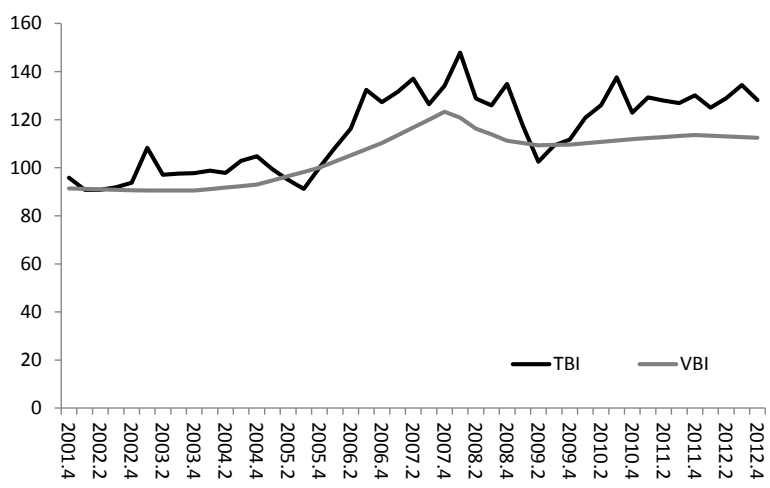

(d) UK

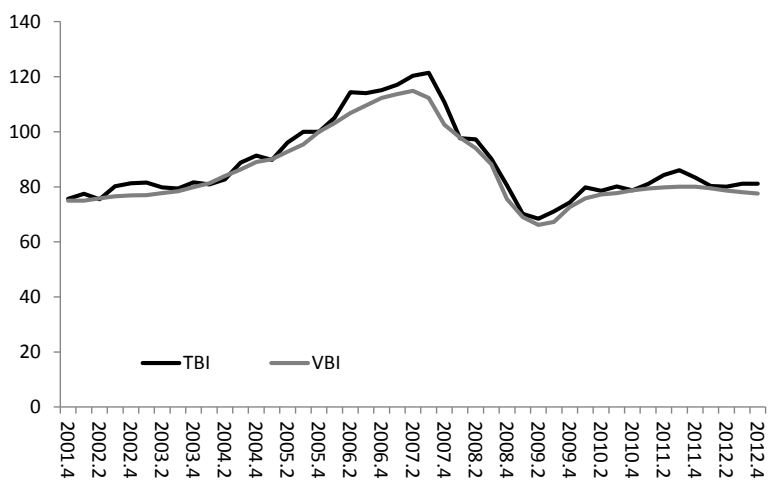

